\title{
MULTIDIMENSIONALITY OF CRISIS MANAGEMENT IN THE EUROPEAN UNION - ANALYSIS OF AN INTEGRATED APPROACH IN TERMS OF CRISIS RESPONSE AT THE POLITICAL LEVEL
}

Keywords: crisis management, crisis response, European Union.

\begin{abstract}
The European Union needs quick and effective support provided in the event of cross-border crises. Following a few dramatic crisis situations such as terrorist attacks, not long after the Member States had to face forest fires, floods or earthquakes. This is when the EU Member States saw the need for joint action in crisis situations. Crisis management ceased to be considered as competences of Member States. It was realized that a joint and coordinated response to crisis situations brings better effects than if a Member State was to tackle them itself.
\end{abstract}

\section{INTRODUCTION}

Crisis management requires a multidimensional approach in acting for the European Union's (EU) internal and external security. The EU's crisis management system assumes cooperation of EU institutions, Member States and joint involvement of various operational instruments. The cooperation scope

1 Monika Potkańska, Assistant professor at the Institute of Political and European Science of the University of Szczecin, monpotk@gmail.com. ORCID ID: 0000-0002-4442-8813 
includes primarily exchange of information and data in terms of prevention, preparation, response, development and reconstruction after the occurrence of crisis situations. It needs to be remembered that the European Union does not have its own resources allowing direct involvement. This is why the crisis management system requires the involvement of Member States with their own, often significant, resources allowing overcoming various kinds of crisis situations. It is essential to work out mechanisms that facilitate taking decisions allowing the EU to get involved in situations necessitating it (RCB, 2018). Crisis response mechanisms needed to be created on the EU forum, including Common Foreign and Security Policy as well as Common Justice and Home Affairs Policy. Over the years, on the plane of the EU's complex institutional architecture, mechanisms for ties in cooperation and coordination of EU bodies and Member States in terms of crisis management have been developed. The crisis management system is embedded in a network of institutional connections creating multidimensional and integrated cooperation between institutions and Member States in the area of broadly understood security.

In view of the above, it is worth looking closely at the mechanism that forms part of multidimensional crisis management. The analysis covered the given crisis management mechanism, i.e. the Integrated Political Crisis Response arrangements (IPCR), which is helpful in taking decisions at EU political level.

The European Union needs quick and effective support provided in the event of crises, including multisectoral and cross-border ones, or in the event of incidents outside of the EU. Crisis management ceased to be considered as competences of Member States. It was realized that a joint and coordinated response to crisis situations brings better effects than if a Member State was to tackle them itself. Only after a few dramatic incidents such as the terrorist attacks of 11.09.2001 or of 2004 in Madrid or of 2005 in London did the EU Member States see the need for joint action in crisis situations.

Today, factors such as technological progress caused by the impact of globalization (which leads to interdependence of countries) and also climate change (which is felt more often and stronger in the form of natural disasters) result in us being at risk of crisis situations. Over the years the Member States have had to face forest fires, floods or earthquakes. Crisis situations of this kind concerned one or more EU countries. Under these circumstances it turned out that support from other EU states was necessary. Naturally, it is the Member States 
who are responsible for crisis management on their territory and for taking a decision on when they need external support.

\section{BASIS FOR THE IPCR PROCEDURE}

The basis for creating a crisis management system was only given by the 2004 Hague programme which called on the EU states to develop integrated solutions in terms of managing cross-border crises (de Miguel Beriain, Macías, Armaza, 2015). Thus, in June 2006, the EU Council could adopt arrangements for the coordination of operations in emergency and crisis situations (Arrangements for Crisis Coordination at EU political level, CCA). They were to foster the exchange of information and coordination of actions by Member States in the event of a serious crisis $(C E U, 2018)$. The CCA agreement was an important step in improving crisis management tools in the EU. It introduced the necessary background for strategic multisectoral coordination of crisis management at the EU level and improved Member States' capabilities in terms of exchange of information on a national crisis situation. Moreover, introducing the CCA created an enhanced pressure for reforms and modernization of the national crisis management system in which the EU Member States are involved. However, the annual exercises carried out as part of the CCA revealed weaknesses, lack of clarity as to the distribution of work and responsibility between the Crisis Steering Group and the Committee of Permanent Representatives (COREPER). During the exercises an incomplete scope of information management was pointed out, where this information was to be provided to the media and the society (e.g. management of text messages and appropriate contact lists) (de Miguel Beriain et al. 2015). Following the review of the emergency and crisis situation coordination procedures the Committee of Permanent Representatives decided to establish the integrated political crisis response (IPCR) arrangements.

One needs to point out Article 222 of the Treaty on the Functioning of the European Union (TFUE), which speculates for providing an EU Member State with aid and support when it becomes an object of a crisis situation ( $R C B$, 2018). Article 222 of the Treaty on the Functioning of the European Union includes a provision that forms a "solidarity clause". Based on this provision, the Union and its Member States acts jointly in the spirit of solidarity if a Member 
State is the object of a terrorist attack or the victim of a natural or man-made disaster. This clause applies to disasters and catastrophes as well as terrorist attacks on the territory of the EU, regardless of whether they occur on land, at sea or in the air. It is to apply irrespective of whether the crisis occurred in the EU or outside its borders. This clause also applies to ships (in international waters) and aircraft (in international airspace) or critical infrastructure (such as offshore oil or gas installations) that are within the jurisdiction of a Member State. Arrangements on the application of the solidarity clause do not replace any existing instruments or policy areas or their detailed launching procedures. They are a general framework in situations of emergency threats and damages that exceed response capabilities of an affected Member State/Member States. In order to enhance capability and avoid duplication of structures and functions, a network approach was adopted. The EU should act only in exceptional circumstances and at the request of the political authorities of the Member State concerned, which is unable to cope with a real or threatening terrorist attack or a natural or a man-made disaster (Council Decision..., 2014).

A Member State affected by a disaster or a catastrophe may invoke the solidarity clause and submits a request to the European Commission, at the same time notifying the Presidency of the EU Council. The competent authorities of the affected Member State contact the Commission's Crisis Response Centre which will play the role of a single contact point working 24 hours a day, 7 days a week at the level of the Union. After involving the solidarity clause, the European Commission and the High Representative, first identify and activate all Union's instruments which may be helpful in responding to a given crisis situations. They include all sectoral, operational and political instruments they have at their disposal. Moreover, the Commission and the High representative must show the instruments and measures within the competence of EU agencies and propose their use. Then, in strict cooperation with the affected Member State, they assess whether the existing instruments are sufficient or whether additional support is necessary, supplemented, where appropriate, by the EU Solidarity Fund. Where appropriate, they present to the Council findings concerning the operational decisions in order to strengthen existing mechanisms, Member States' decisions on extraordinary measures provided for in the existing instruments; policy coordination and information exchange; operational measures or measures to support Member States' rapid response 
(Council Decision..., 2014). Each Member State invoking the solidarity clause will receive help under the IPCR.

\section{THE IPCR PROCEDURE}

The European Union's integrated arrangements for crisis response at the political level (IPCR) have been developed to facilitate timely coordination and response at the Union's political level in the event of a major crisis. The IPCR also supports coordination at the political level in response to triggering the solidarity clause (Article 222 TFEU). In other words, the crisis coordination mechanisms may be activated in two ways, i.e. by the Presidency and by the Member State triggering the solidarity clause. Standard IPCR operational procedures established actions that need to be taken (Commission Recommendation..., 2017). Depending on the situation, there are three operational modes:

- "monitoring" - simple exchange of existing crisis reports,

- "information-sharing" - creation of analytical reports (Integrated Situational Awareness and Analysis, ISAA); as part of gathering and distributing information and of an analysis of a current situation, a safe web platform (IPCR Web Platform) is created. The Platform may be used by the stakeholders at appropriate levels in the Member States and the European Union.

- "full activation" - preparation of proposals for EU action to be decided upon by the Council of the EU or the European Council (CEU, 2018). The IPCR mechanism is best illustrated by the figure below with a detailed description of procedures.

The IPCR can be used according to the level of the crisis by moving from the 'monitoring mode', to the 'information-sharing mode' which is the first level of IPCR activation, and 'IPCR full activation. The decision on activation in full mode is made by the current Presidency of the Council of the EU. The Commission, EEAS and the General Secretariat of the Council of the EU (GSC takes action related to the activation of the entire system and brings together all existing EU crisis management systems and mechanisms) can activate the IPCR in the information-sharing mode. In the monitoring and information-sharing modes different levels of information exchange may be triggered, where the 
information-sharing mode demands the production of ISAA reports (Commission Recommendation..., 2017).

Figure 1. Standard IPCR procedures

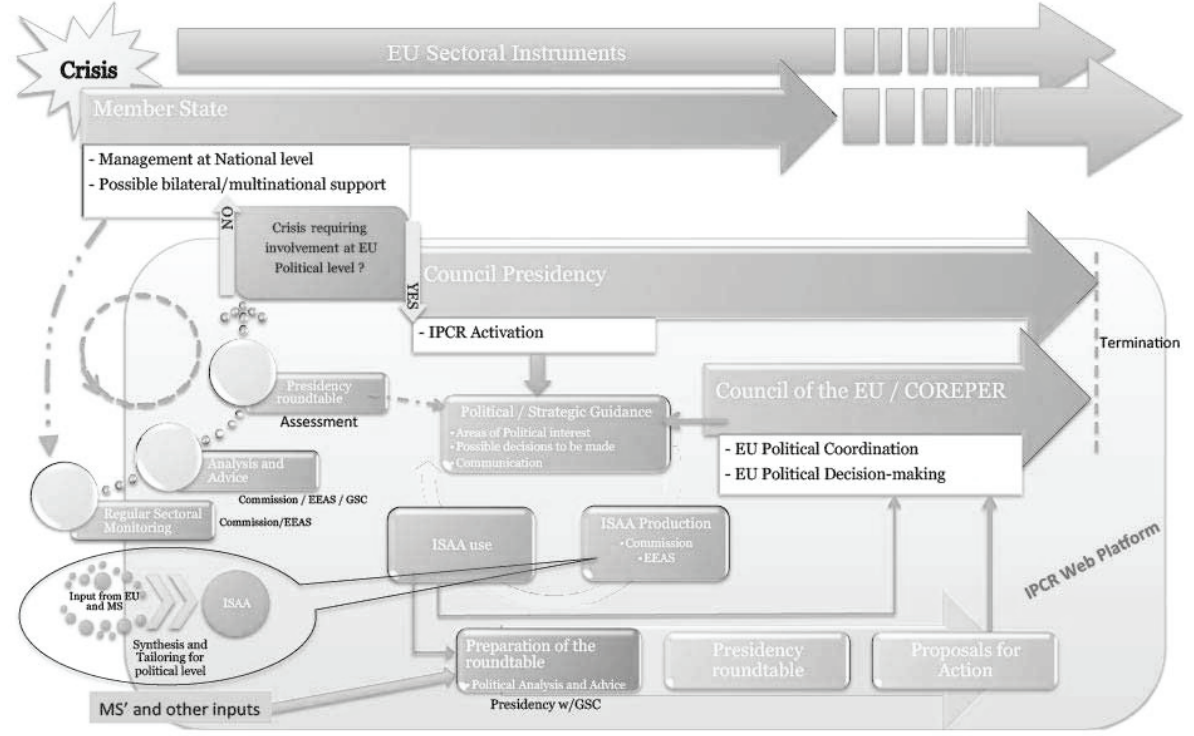

Source: http://data.consilium.europa.eu/doc/document/ST-10708-2013-INIT/en/pdf.

In the monitoring mode (IPCR not active), situational reports and notifications from the Presidency of the Council of the EU are provided as well as guidelines on the development of the crisis situation and its possible changes, which may devolve into a crisis with consequences for the EU. Based on available data from monitoring and alerting, the Commission services, the EEAS and the GSC keep each other informed on possible developments, in order to be ready to advise the Presidency for a possible IPCR activation (in full or in the information-exchange mode). Then the Presidency evaluates the need for political coordination, information exchange or decision-making at the EU level. To this end, the Presidency may convene an informal round table meeting. The Presidency carries out an initial identification of the areas requiring the involvement of COREPER or the Council. This forms the basis of the guidance for the production of Integrated Situational Awareness and Analysis (ISAA) reports. Having taken into account the characteristics of the crisis, its possible 
consequences, the Presidency takes a decision on the application of the IPCR procedures (Commission Recommendation..., 2017).

Upon activation of the IPCR "information exchange" mode, a crisis page is generated on the IPCR web platform, allowing specific exchange of information focusing on aspects that will provide basis for creating the ISAA and will contribute to the preparation of the discussion at political level. Member States provide data for Commission services and the EEAS by means of the IPCR forms, depending on the circumstances and the crisis situation. The entity responsible for creating the analytical report is the Commission services or the EEAS depending on what events we are dealing with (Commission Recommendation..., 2017).

In the IPCR full activation mode, the Presidency gathers an informal round table to review the situation and items to be focused on. The informal round table meeting is also the forum to develop, review and discuss all proposals for action to be submitted to COREPER or the Council. Based on the results of the informal round table meeting, political coordination is undertaken and decisions are made at the level of COREPER or the Council. The coordination of response activities is performed at all levels and exceptional measures are applied. The decisions taken refer to political declarations and are also a guidance for updating the reports at the political and strategic level. Then, information is provided based on the ISAA reports on the evolution of the crisis and on the impact the political decisions taken had on the crisis. This feedback loop supports the Presidency in taking decisions on further involvement of the EU political level or on phasing down the IPCR. In taking a decision on further action, the Presidency convenes an informal round table meeting to assess the need to maintain the IPCR active or perhaps to take the decision on its closing or downgrading the level of activation (Commission Recommendation..., 2017).

\section{CONCLUSION}

The European Union's integrated approach concerning crisis response at the political level (IPCR) is a modern and promising mechanism serving to improve the efficiency of coordination and management in crisis situations at the EU level. Based on the analysis it seems that this mechanism allows quick and 
effective coordination. As part of this mechanism, the Presidency was given the task of coordinating joint action, taking decisions at the intergovernmental level and creating analytical reports (ISAA) while general competences introduced in the concept and management of gathering and providing data by means of the IPCR web portal are sufficiently essential to conclude that the mechanism is efficient enough to support Member States in crisis situations (de Miguel Beriain et al., 2015). The IPCR forms part of the Union's crisis response system. Through this mechanism the Presidency coordinates the political response to a crisis, involving EU institutions, Member States and other EU actors and mechanisms in the activities.

Exercises on crisis response with the participation of the European Union and Member States are carried out regularly. On 28 September 2017 the European Union launched an exercise to test crisis management mechanisms in response to cyber and hybrid threats (European External Action Service (EEAS)).

The IPCR was activated during migrant inflows to the European Union in 2015 which caused a crisis situation. In view of that, the Luxembourg Presidency decided on 20 September 2015 to activate the IPCR in the "information exchange mode". Its aim was to monitor the development of migration movements in order to support the decision-making processes and to appropriately implement agreed measures. Then, on 9 November 2015 the Presidency moved on to the next stage and fully activated the IPCR mechanism. On its initiative, regular consultations with competent experts began in order to mitigate the migration crisis at the EU level. Activating the IPCR procedure in a crisis situation of migration inflow involved identification of needs, problems and appropriate coordination of activities. Exercises in crisis response to test the IPCR are being carried out (EEAS).

\section{BIBLIOGRAPHY:}

Council Decision of 24 June 2014 on the arrangements for the implementation by the Union of the solidarity clause (2014/415/EU), OJ 1192/53, 01.07.2014.

Commission Recommendation (EU) 2017/1584 of 13 September 2017 on coordinated response to large-scale cybersecurity incidents and crises, OJ L 239/36, 19.09.2017. Downloaded from https://eur-lex.europa.eu/legal-content/EN/ TXT/PDF/?uri=CELEX:32017H1584\&from=PL. 
EU launches exercise to test crisis management mechanisms in response to cyber and hybrid threats. Downloaded from https://eeas.europa.eu/headquarters/ headquarters-homepage/32969/eu-launches-exercise-test-crisis-managementmechanisms-response-cyber-and-hybrid-threats_en.

Finalisation of the CCA review process: the EU Integrated Political Crisis Response (IPCR) arrangements, doc. 10708/13 Council of the European Union. Downloaded from.

http://data.consilium.europa.eu/doc/document/ST-10708-2013-INIT/en/pdf.

Miguel Beriain de, I., Atienza Macías E., Armaza Armaza E.J., The European Union Integrated Political Crisis Response Arrangements: Improving the European Union's Major Crisis Response Coordination Capacities. Downloaded from: https://www.researchgate.net/publication/273699997_The_European_Union_ Integrated_Political_Crisis_Response_Arrangements_Improving_the_European_Union's_Major_Crisis_Response_Coordination_Capacities.

The Council's response to crises (IPCR). Downloaded from https://www.consilium. europa.eu/en/policies/ipcr-response-to-crises/ (01.12.2018).

Współpraca w ramach Unii Europejskiej, downloaded from http://rcb.gov.pl/ wspolpraca-w-ramach-unii-europejskiej/ (20.11.2018). 